\title{
Multicultural Museum Education in and beyond Exhibit: Local and Transnational Synergies from Canada's Oldest Chinatown
}

${ }^{*}$ Tzu-l Chung

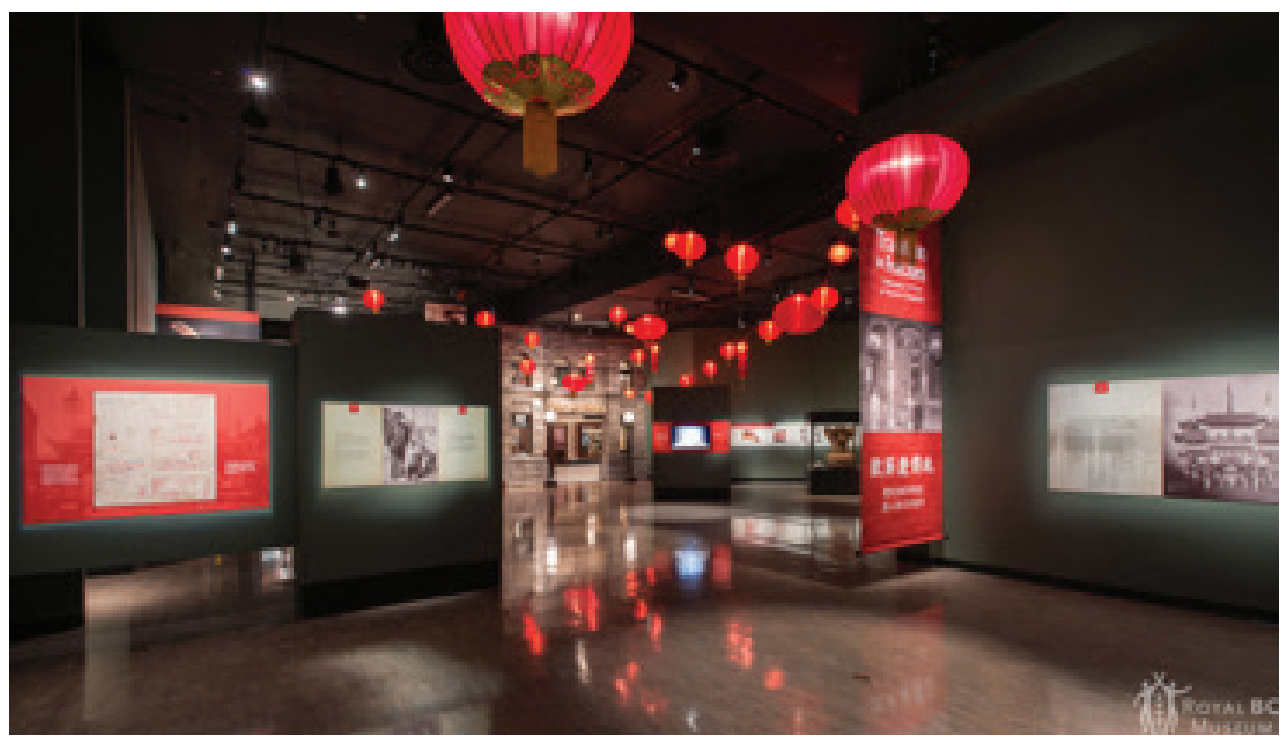

Figure 1. Tradition in Felicities Exhibition at the Royal BC Museum. Image courtesy Royal BC Museum

\section{Abstract}

In2013, aspartof'AChinatownCelebration,'amonth-longfestival celebrating Canada's oldest Chinatown, the Royal BC Museum (RBCM) mounted a temporary exhibition Tradition in Felicities: ${ }^{1}$ Celebrating 155 Years of Victoria's Chinatown (TiF) (Figure 1). The exhibit also celebrated the Chinese Freemasons' $150^{\text {th }}$ anniversary in Canada.

TiF featured a unique centerpiece: a handcrafted lantern created in the 1930s by Victoria's Chinese Freemasons, one of the oldest Chinese organizations in Canada (Figure 2). It is the oldest-known such lantern in North America and Southeast Asia. 'Objects,' as scholars of material culture point out, 'help [people] to know, understand, and situate [them]selves within the world, both externally and internally'(Clouse 2008: 6). The connections of objects to lived experiences render them historically and culturally meaningful. In tracing the history of the lantern, we consulted both members of the Chinese Freemasons, including elder Jon Joe who helped to identify the names listed on the lantern, and Chinatown's former residents and descendants, in accordance with the RBCM's practice of multicultural community outreach and participation.

This lantern engages diverse audiences and inspires a cross-cultural aesthetic 




Figure 2. Chinese Freemasons Lantern before Conservation Treatment.Image courtesy Royal BC Museum appreciation through its Chinese, trans-Pacific, international and Canadian connections. Handcrafted in Victoriabyamasterfrom Hong Kong, the lantern is based on the classic Chinese tradition of the running horse lantern, which is more than 2000 years old. ${ }^{2}$ The top panels present the Chinese Freemasons' international icon; in the middle are intricate moving details in Chinese calligraphy couplets and paintings in the traditional running horse lantern design; and, on the base, a list of local sponsors and contributors. A diagram within the exhibition explained the different elements of the lantern in detail. The top and bottom panels convey the artifact's connection to local and regional history. The Chinese Freemasons' westernized icon reveals its transformation from a secret society in Qing China to an international society of Chinese Freemasons after entering the Americas, indicative of the transnational context of the migrant culture in Chinatowns. The bottom panels epitomize the composition of Victoria's Chinatown: long-term businesses, settled resident families who developed roots in Canada, and a few sojourners who eventually returned to their birthplaces in China.

For a provincial museum such as the Royal BC Museum (RBCM), where I am a curator, one of our mandates is education - to share knowledge about British Columbia with the world. At the same time, increasingly complex cross-cultural and transnational perspectives reflect concerns for broadening the framework of knowledge sharing and museum education in a multicultural context. ${ }^{3}$ The new framework allows us to examine cultures informed by both the concept of globalization, as the homogenizing effect of integrated market capitalism often associated with multinational corporations, and the 'hybridities and fluidities' of the transnational aspect of this world system from multidirectional contacts between nations, cultures and individuals. The TiF project can be used as a case study of museum education from transnational perspectives, to address Klaus Müller's question: 'can museums propose or even help shape a different model of a global society than the one being advanced by multinational corporations?' (2003) Through sharing, and raising the awareness of, local, diverse, 'hybrid' and previously hidden stories of a formerly underrepresented group, the Chinese population of Victoria can, through a small exhibit, counter the homogenizing effect of globalization and educate people about social justice through intercultural understandings of other groups' experiences. This group was not presented as a homogenous one. Their stories captured diversities in class and gender and 
were contextualized to resonate locally, nationally and transnationally.

The first section of this essay provides an overview of the integrated process of both multicultural community outreach and engagement, and museum knowledge production and education that advanced the understanding of historical injustice from the perspective of the insiders. The second section examines how this process reunited this previously marginalized group and engaged new transnational audiences. The process inspired educational moments that are unique to museum settings through forging local synergies and revealed in the diverse visitors' feedback. As the Adult Learning Team Lead at RBCM acknowledges, while it is not easy to measure educational outcome in informal settings such as museums, first tier outcomes, in this case the comment book, can be analyzed to get a better sense of whether our long-term goals might be reached. ${ }^{4}$ Following the guidelines set out by Inspired Learning for All, the RBCM looks for evidence of exhibits affecting visitor attitudes and values, such as opinions or attitudes towards other people and the RBCM in relation to an experience, and increased capacity for tolerance. ${ }^{5}$ These key indicators are measured in this section to understand TiF's educational impact.

The third section proposes a continuing cross-cultural educational program as a legacy of the exhibition in the form of a trilingual (English, French, and Chinese) video which, through information and communications technology (ICT), will be available online and in educational institutions, inspiring interest and sharing knowledge not only within the RBCM's walls but also with a wide range of audiences. This ICT project moves museum education beyond institutional walls and tests educational possibilities of museum knowledge. It is a new museum multicultural education initiative, the outcome of which is yet to be measured.

\section{The TiF exhibition in the provincial museum and its cultural context}

As Smithsonian Museum scholar Stephen E. Weil stated in the title of his essay at the turn of the millennium, museums should transform 'from being about something to being for somebody'(Weil 1999: 229). In our current museum practice, that 'somebody' is the diverse and constantly changing communities that we serve, whether they be established local residents, new immigrants, or visitors from around the world.

The RBCM works with the local Chinese community to share their stories from their perspectives in English and Chinese, the official written languages used in early Chinatown. Founded in 1858 at the time of the gold rush, and once the second largest Chinatown in North America after San Francisco, Victoria's Chinatown had an estimated population of several thousand in the 1880s. We study the stories from this historic enclave from which not many individual voices have surfaced.

At the time the lantern was made and displayed in Victoria's Chinatown in the 1930s, the Chinese had long suffered from racial discrimination. Even the locally-born were denied the right to vote or to participate in many forms of employment. ${ }^{6}$ From 1886 to 1923 Canada limited the immigration of Chinese, and from 1923 to 1947 banned it completely. Informal practices of segregation meant that many Chinese-Canadians grew up within, or were associating with, Chinatown. Not until the mid-twentieth century, when racial barriers broke down, did Chinatown cease to be a residential enclave (see Roy 1989 and 2003).

The exhibit engaged visitors as interactive knowledge producers rather than just passive receivers through a context that encouraged intercultural understanding - making connections through differences. Museum studies scholar Sharon J Macdonald explains,

museums not only exist within a particular time and space, [but] also help articulate particular temporal and spatial orders. It is in this respect that we can see them as not just existing within a context but also as themselves creating cultural contexts. (Macdonald 1996: 8) 
The RBCM provided a multicultural and transnational context for the local stories. To facilitate visitors to connect with and, more importantly, move beyond this created context, the exhibit's feedback stations invited visitors to consider their transnational connections to the local stories and characters. Thus, the context was being constantly redefined by visitors, many of whom related to the local stories through various connections, such as other Chinatowns in the world.

As a provincial museum, the RBCM has a long tradition of engaging community participation in the planning, development, and presentation of exhibits ${ }^{7}$ to give voices to publics previously underrepresented, and to respond to their 'social, cultural and educational' needs by affirming 'the worth and contribution of minority peoples' (quoted in Simpson 1996: 75). For example, in 1992, through collaboration with and advice from the local ChineseCanadian communities, the RBCM acquired one of the oldest herbalist shops from Chinatown and added the Chinatown Alley to its Old Town permanent gallery (see Lai 1994a \& 1994b). In February 1994, the RBCM mounted an exhibit in collaboration with the Black community to celebrate Black History Month. ${ }^{8}$ A travelling exhibit, Festa Italiana: Celebrating BC's Italian Communities, invited the Italian communities to share their stories and show their families' artifacts. In 1999, the exhibition HuupuKawanum Tupaat: Out of the Mist: Treasures of the Nuu-chah-nulth Chiefs, was the result of collaborative efforts with the Nuu-chah-nulth Tribal Council (Kreps 2003: 156-7).

Given this tradition and the RBCM's work on community history projects, in 2012 local Chinese-Canadian community leader and Victoria City Councillor, Charlayne Thornton-Joe, suggested that the RBCM create a temporary exhibition as part of the 2013 'Chinatown Celebration' in Victoria. This was an opportunity for the RBCM to showcase its work to preserve the province's multicultural history on a small scale in a single-object exhibition. ${ }^{9}$

To convey and contextualize the stories of this lantern, the exhibit included archival images, digital animation of the lantern, a live conservation project on the lantern, oral history, the feedback station, and Chinese New Year's decorations, made by teachers and students of the local Chinese school, ${ }^{10}$ in the museum's Chinatown Alley.

After much consideration and discussion between the curator and designer, the history of the Chinese community and the discrimination it once faced were expressed in the archival image wall. The wall showcased the transnational context in the second half of the nineteenth century that brought Chinese to the region, as well as close-up looks at their lives in British Columbia. By zooming in on their lives and their contributions and hardships in Chinatown and industry, this image wall set the historical context of Victoria's Chinatown as a nineteenth century gateway between Asia-Pacific and North America, and as an economic centre linking the interior of British Columbia to the world beyond. As an entrepôt, Victoria's Chinatown was an important site for the Chinese-Canadian community when the lantern was created. One visitor noted:

Showcasing racism in Canada is very challenging, I expect, and I really like how
the exhibit conveys the harsh reality for those immigrants to Canada but also
their pioneering spirit, sense of family and community, and amazing work ethic. In
other words, your exhibit has a meaningful balance of the negative and positive. ${ }^{11}$

In the exhibit, educating visitors about the issue of discrimination was performed through embedding it as an overarching context. We also interviewed community participants whose stories helped to deliver the ultimate educational messages of the impact of racial prejudices and discrimination on individuals and groups, of 'the worth and contribution' of a previously marginalized group (quoted in Simpson 1996: 75), and the need for social and political justice to all. Those who grew up in Chinatown in the 1930s and 1940s are now in their late 70 s, 80 s or early 90 s. To help visitors understand the specific time and space in which the lantern was created, we featured interviews with elders from four families of diverse social classes and backgrounds emblematic of the traditional Chinatown members: a Chinatown leader and large business owner, the operator of a small business, a contract laborer, and a veteran. The four family interviews together revealed patterns in their collective memories. From an era characterized by discrimination, all elders remembered a close-knit community, brought together by united efforts of supporting each other, traditional holidays, and, most significantly, the warm feelings about a supportive communal life despite racism and the lack in material goods. 


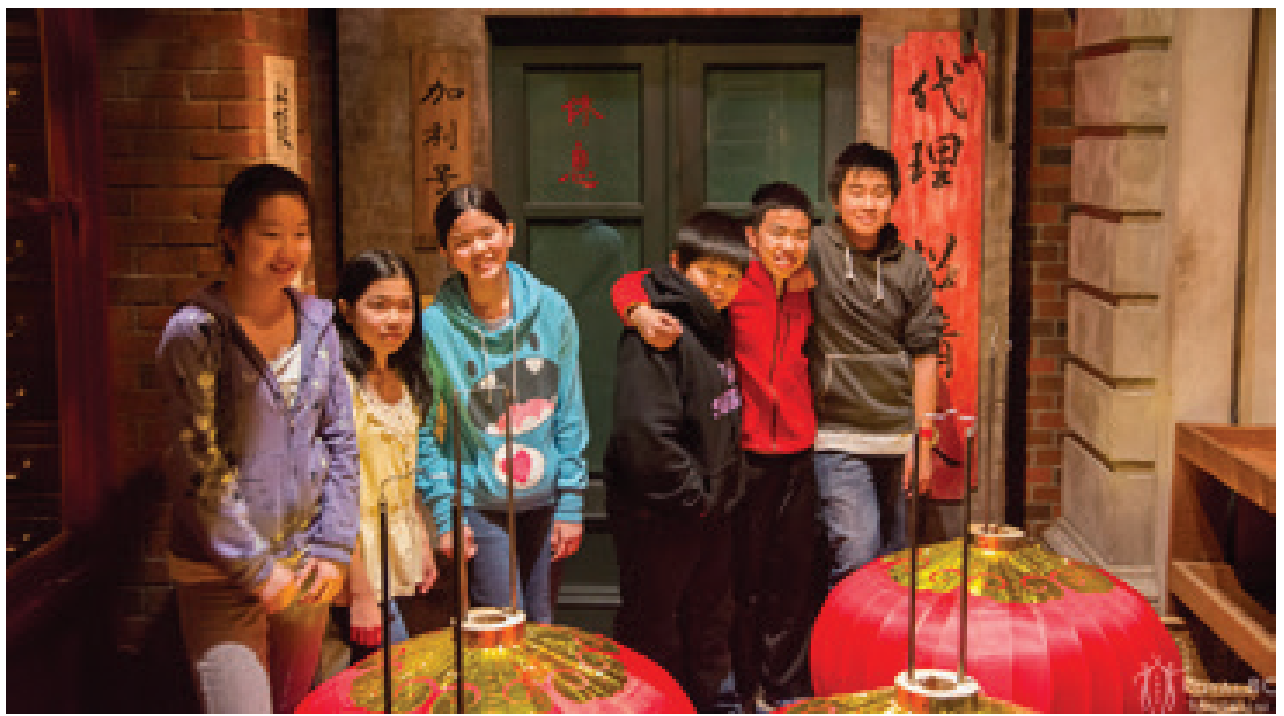

Figure 3. Victoria Chinese Public School students decorating the gallery. Image courtesy Royal BC Museum

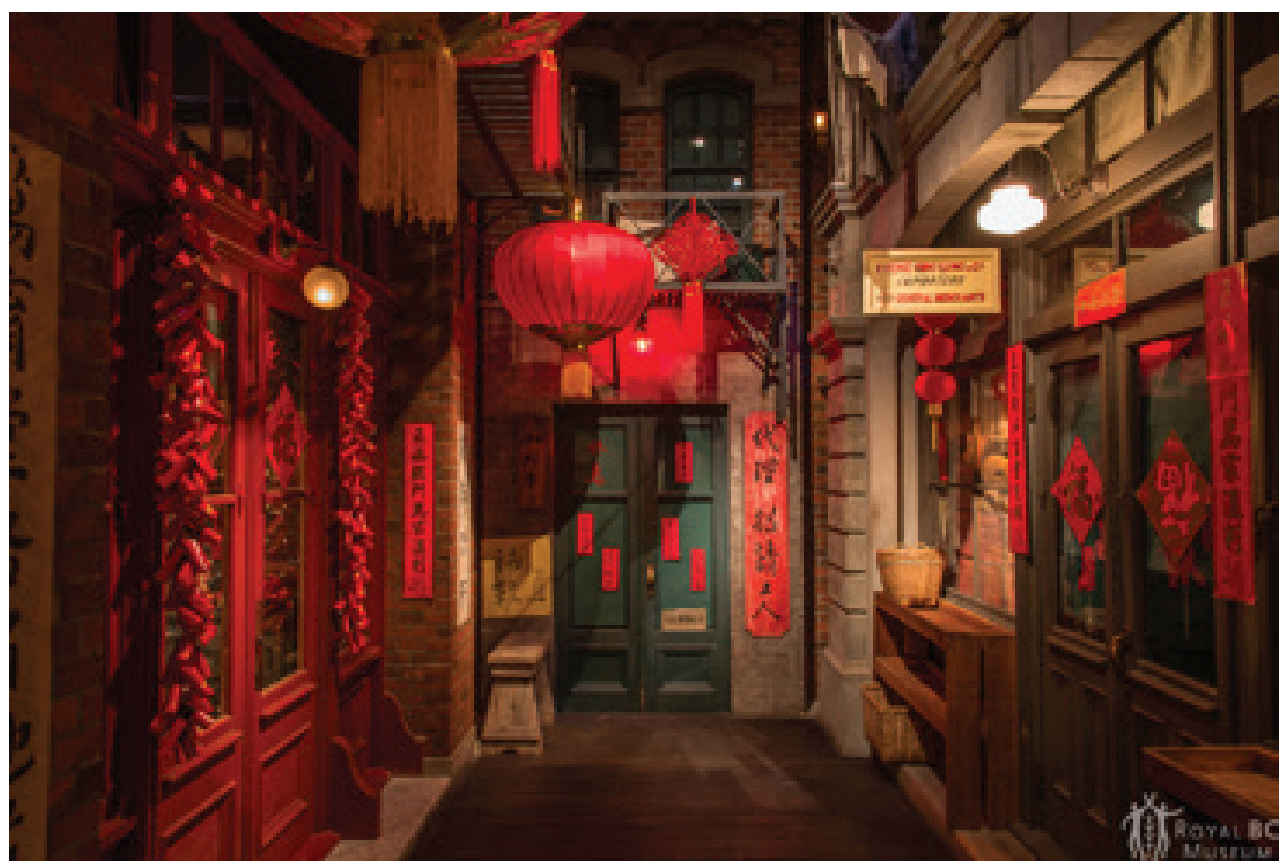

Figure 4. Chinatown Alley in permanent gallery decorated for Chinese New Year. Image courtesy Royal BC Museum 


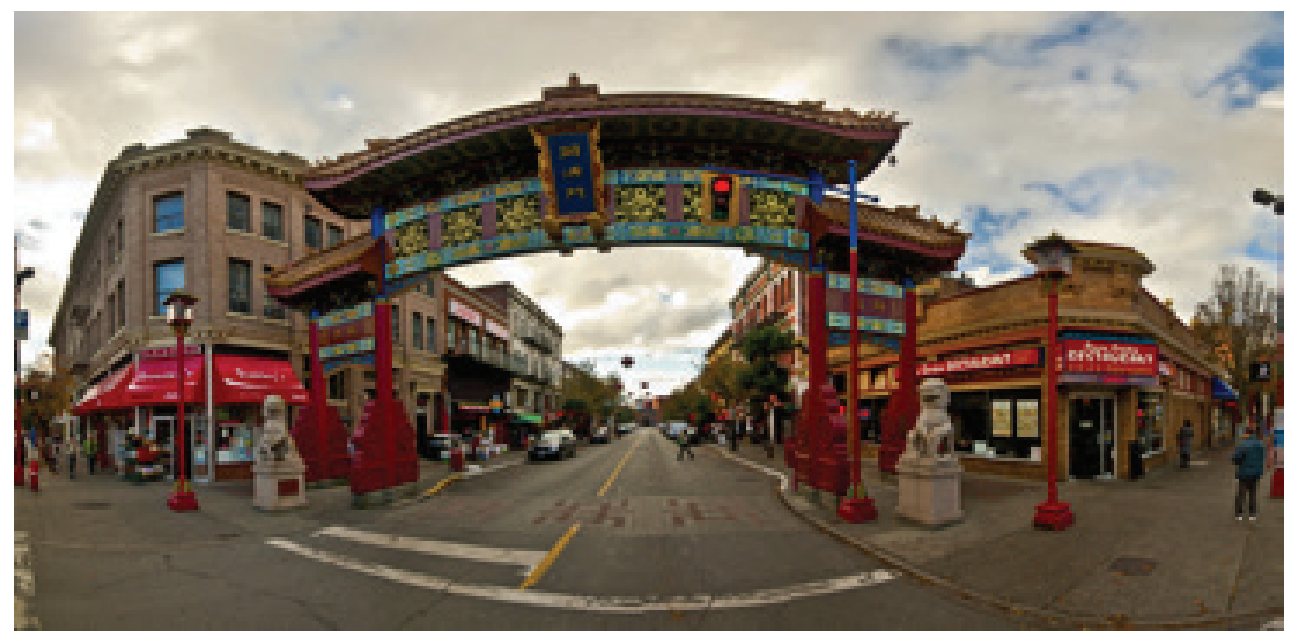

Figure 5. Victoria's Chinatown. Image courtesy Royal BC Museum

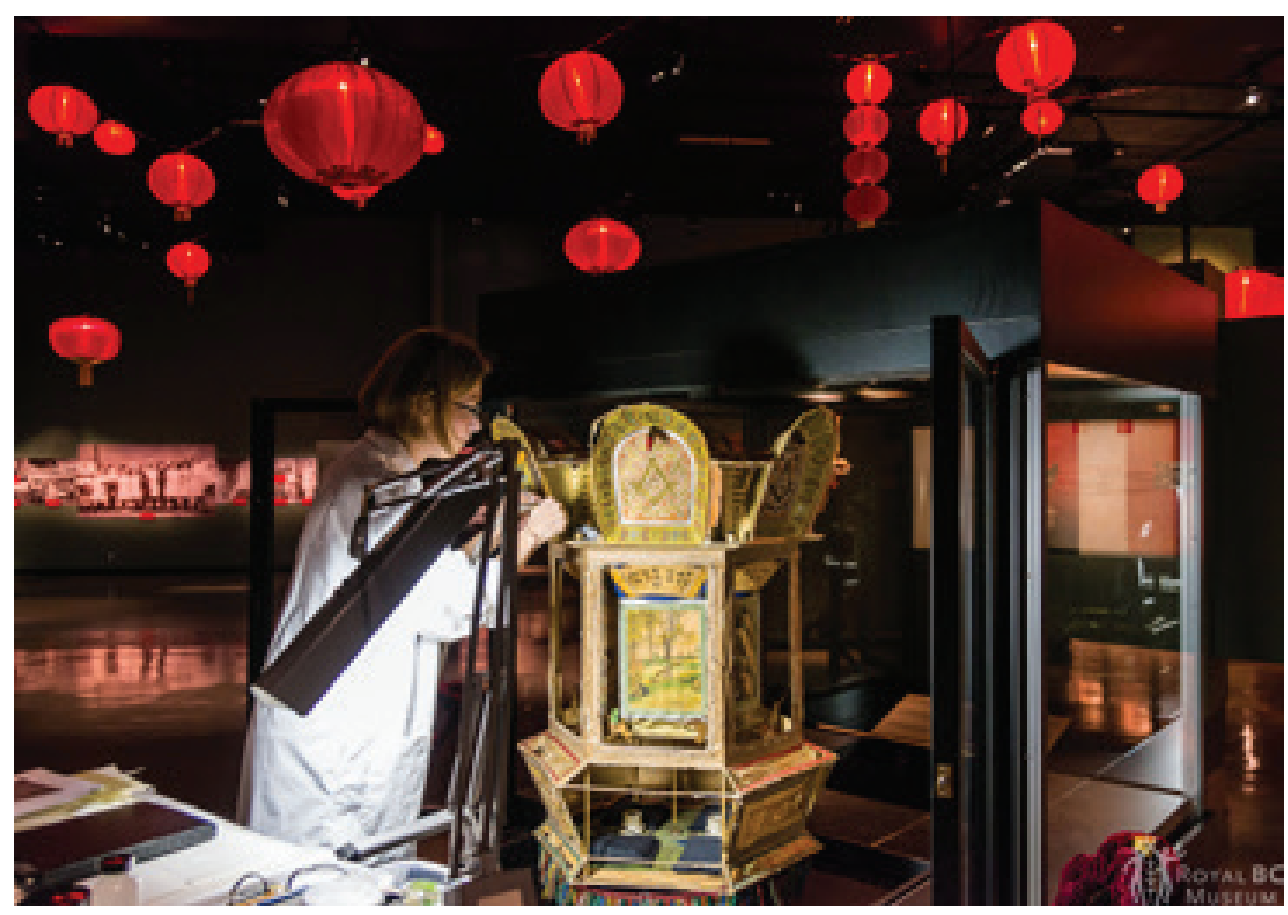

Figure 6. Gallery Lantern Conservation Project in Progress. Image courtesy Royal BC Museum

To communicate the connections among different aspects of Chinatown's stories that are inclusive of community voices and participation, the exhibition built a special pathway to connect the Chinatown Alley to the Old Town Gallery. As part of the façade of the nineteenthand early-twentieth-century Old Town gallery, the Chinatown Alley was originally designed to 
represent the non-Chinese perception of a secluded Chinatown, and to give some glimpses into authentic store interiors. Thus connected to the representation of that secluded space and era, the lantern and interviews not only brought history to life but also highlighted the insiders' perspectives and stories. To complete the vision of this early life in times of felicities, the Victoria Chinese Public School Principal, teachers and students (Figure 3) helped decorate the Chinatown Alley for the Chinese New Year with art work, lanterns, and Chinese knots. ${ }^{12}$ (Figure 4) Through different forms of community support and engagement, the TiF Exhibition opened with the beginning of Chinese New Year, the Spring Festival of 2013.

Complementing the family stories and the specially decorated Chinatown Alley was a videoed talk by 'Canada's Mr. Chinatown,' Dr. David Chuenyan Lai, who outlined the geographic and historical significance of Victoria's Chinatown. Situated at the north edge of downtown Victoria, Chinatown today is primarily a tourist attraction and occupies little more than a city block (Figure 5). It has some stores, restaurants, a Chinese school, and meeting places for Chinese-Canadian organizations and traditional clan and other associations where elders still gather. Dr. Lai also explained the important Chinatown restoration project that he led in 197981 , which contributed to the preservation of historical buildings. This oral history video station attracted enthusiastic comments: "Blown away on all the "Mom \& Pop" stores. Chinatown is very cool!' or 'The videos are most informative. Well worth watching each one. This is an excellent overview of our Chinatown history.' The educational intention to inspire interest in this specific history and landscape was evidently achieved through the historical overview, the first-person narratives and media components.

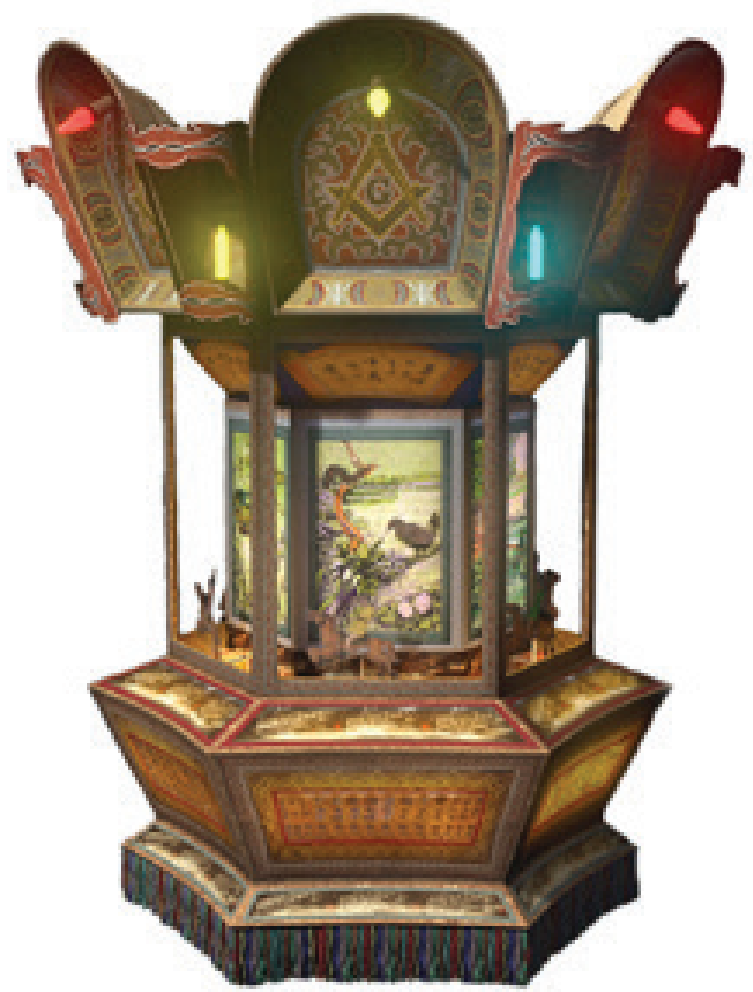

Figure 7. A snapshot of digital animated image of the lantern. Image courtesy Royal BC Museum
The lantern, of course, was the centerpiece. To show how the museum cares for artifacts, the exhibition had a conservator on site who worked not to restore it to its original state but to stabilize it in order to preserve its original design and period integrity (Figure 6). To complement this live conservation work, a digital animation project illustrated its full glory in its original rotating, glowing and moving state (Figure 7) and the technical theory of a running horse lantern. A few visitors commented in positive ways, such as: 'I found the Chinese lantern very interesting. I loved how [the digitization] showed the different pieces that moved. Thanks.' The meticulous conservation work and the digital presentation together encouraged aesthetic appreciation for the original artifact, highlighting its cross-cultural and transpacific connections as well as illustrating a form of informal museum education through the use of both 'the precious original' and 'its precious reproduction' (Müller 2002: 27). To me, this interactive form of museum education promotes intercultural understanding and is unique to the museum setting. 
To meet the demands of diverse visitor questions, the conservator developed a FAQ factsheet by drawing on both curatorial and conservation knowledge about the lantern, and trained a team of volunteers to assist in this interactive gallery conservation project. A typical visitor response was: 'Wonderful to see the actual working and importance of History. Thank you!' A visitor from Seattle commented: 'Liked seeing conservators work because it made the exhibit items seem realistic, and glimpse the process of a museum behind-the-scenes, know what actually happens when something is donated.' In terms of observable engagement with the exhibit, the one-on-one interactions between conservators, volunteers and visitors alongside the digital animation proved to be an effective form of museum education. As one visitor from West Virginia commented, 'I enjoyed the opportunity to learn about this. I think it is a great program, highly educational.' Some other visitors recommended touring this live conservation project to bring this form of museum education to the road in order to reach a wider audience.

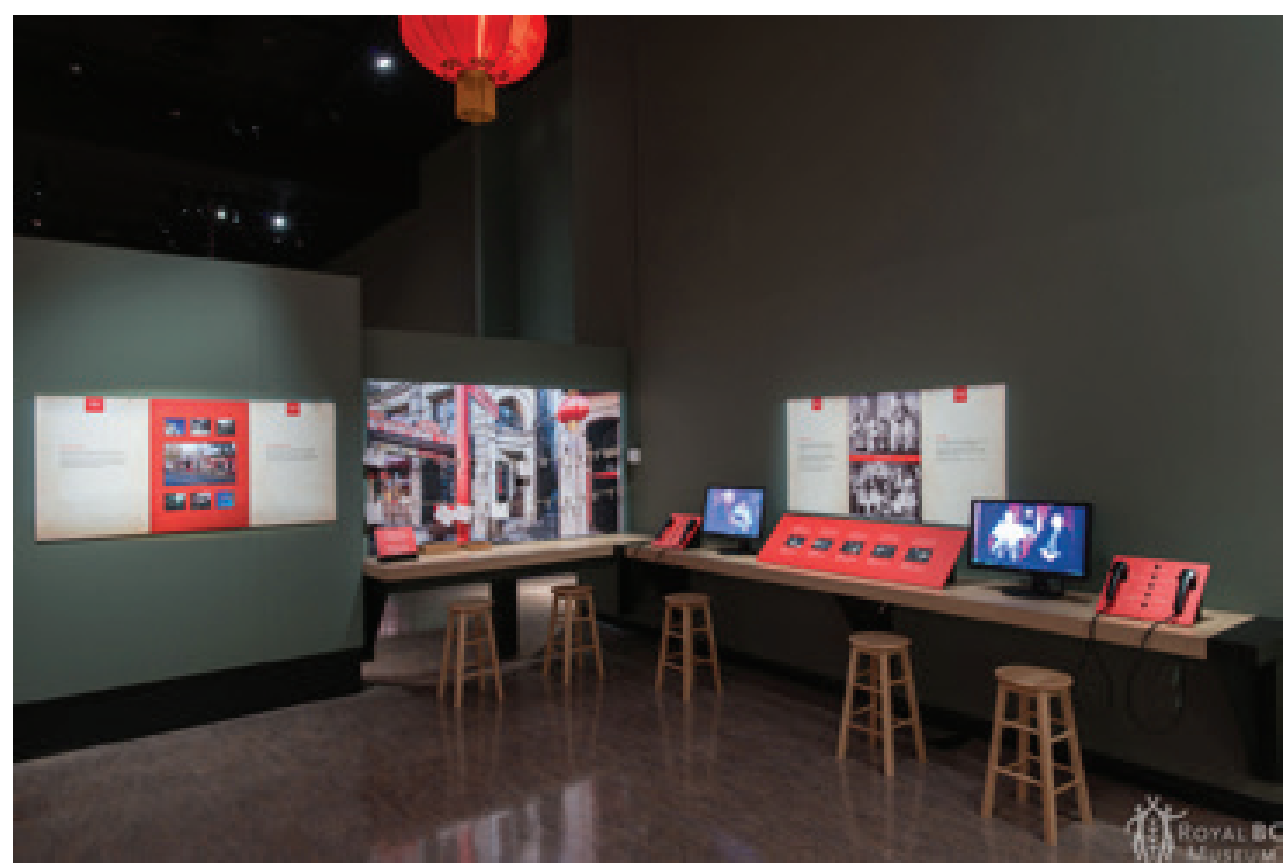

Figure 8. Community interview and feedback station. Image courtesy Royal BC Museum

\section{Local and Transnational Synergies in Community Building and Identity}

Through community outreach and participation, the juxtaposition of the diverse elements in this exhibition unexpectedly brought out hidden memories and rekindled the synergies of a marginalized group's strong family and communal bonds, thus creating an intangible form of museum education and bringing communities closer together. It engaged the second- and third-generation Chinese-Canadians through expressions of family and communal experiences from Canada's Exclusion Era, and helped visitors imagine life for Chinese-Canadians of that time. The synergies forged by this exhibition through community participation culminated with a reception at the museum attended by local community leaders and members of these second- and third-generation Chinese-Canadian families. The speakers included the mayor of Victoria, the first Canadian-born Chinese Member of British Columbia's legislative assembly, the President of the Chinese Consolidated Benevolent Association who was also the Chairman of the Headquarter of the Dart Coon Club (the Chinese Freemasons) in Canada, and Frank Low, whose grandfather's name appears on the Chinese Freemasons Lantern. 
A special educational moment for all occurred when the local community leader, Charlayne Thornton-Joe, pointed to the unprecedented synergies gathered in the room from the reunion of the 1930s Chinatown community, something very rare, as the elders had been dispersed for decades. Her father Jon Joe, a key leader and active member in that community, volunteered, among other things, for service in the Canadian Army during World War Two in the hope that this would lead to the enfranchisement of Chinese-Canadians. In his early nineties, Joe assisted with this exhibit from behind the scenes research to sharing stories in front of the camera. Although he and Thornton-Joe were featured in one of the interviews, she did not mention it in her address at the opening reception. Rather, she pointed out that the most valuable part of this exhibition was not its visible or physical aspects but the intangible synergies re-uniting the people who once lived in a close-knit and mainly secluded community. In keeping with community sensibilities, Thornton-Joe expressed her long-standing hope to reunite this community group. Family interviewees also shared with me after the reception how much joy it brought them to be part of that group and to see the childhood friends again.

These synergies demonstrate the importance of the process of community engagement in museum projects which not only mirror, but create innovative educational spaces and motives for expressing, collective social and political needs for communal relationships and justice. 'Museums are never just spaces for the playing out of wider social relationships; a museum is a process as well as a structure, it is a creative agency' (Karp and Lavine 1991: 1). The RBCM was more than 'a mediator between the ethnic community and the larger public' (quoted in Loukaitou-Sideris and Grodach 2004: 54), but also an active participant in educating about and facilitating 'community building and sustainability' (Loukaitou-Sideris and Grodach 2004: $55)$. In the age of globalization, local community building and sustainability is an integral part of our daily challenges as museum practitioners who strive to be active agents for social change through museum education.

Joined together in the pursuit of historical knowledge for the TiF project, both the museum and this particular community drew from this educational moment - the project educated the communities about the historical significance of their collective lived experiences, and the museum about the intangible communal significance of the knowledge gathered from creating this space for engagement as well as about the origins and contexts of parts of its collection. ${ }^{13}$

This informal museum education therefore informed the re-forging of the community identity and continuing community building and participation. During the planning of the exhibition, there was 'the need to interrogate what constitutes a community, local, regional, or national context as a site for cultural construction' (Kreps 2003: 159). This specific community identity was local (Victoria and British Columbian), national (Canadian), as well as transnational (trans-Pacific family, cultural, political, and economic connections). On the local level, the interviewees shared 'sentiments of belonging' (Macdonald 2003: 2) from lived experiences together. Yet their Canadian identity was essential to all the interviewees and their extended families. This national identity held special meaning for that particular generation who lacked citizenship rights. Accordingly, this identity is not an 'imagined community' - something that naturalizes the presence and hierarchy of the nation-state in Benedict Anderson's definition (see Anderson 1983, Daugbjerg \& Fibiger 2011: 136, and Macdonald 2003: 2-3) - but instead a shared sense of community, built from communal experiences partially reinforced by external social and political circumstances and their fight for justice. The Canadian identity therefore meant not only a sense of belonging to an imagined community, but also to the nation as the 'final triumphant stage of successive progression' (Macdonald 2003: 2-3). The communitybased exhibition thereby achieved its educational goal of raising the awareness of the social issues of racism and the previously marginalized community's experience and contribution.

Through community outreach, engagement, and informal education, the exhibition promoted intercultural understanding in its engagement of new audiences of different generations of Chinese-Canadian community members, their friends, and extended families beyond their communities. Because early Chinese communities in the Victoria and Vancouver Chinatowns were connected through marriages, cultural and economic ties, and activities, Chinese-Canadians from that generation in Vancouver also found resonance and childhood friends in the lantern's stories and the interviews. In fact, alongside the positive feedback, these community members urged us to develop more such exhibits so they could share their 
heritage and history. ${ }^{14}$ Non-Chinese visitors agreed: 'I am so surprised that there's a Chinatown show! Love it so much. Awesome.' and 'Tons of new information. This should be done more often' (New Orleans). This call for future museum exhibitions on similar subjects testifies to the resonance and educational impact of this exhibition on the local and international communities.

Besides the live conservation project, a feedback station provided an interactive educational element and encouraged visitors to make connections and contribute (see Figure 8). In front of the picture wall of the Chinatown façade, we invited visitors to reflect on and share their own stories:

'Everyone has a story. We would love to hear from you. Please sit down and write a personal memory of Chinatown, then post it above.... These stories about Victoria's Chinatown are not exclusive and do not end here. How do your lives and your memories relate to them?' (RBCM TiF exhibition)

Some visitors indeed shared valuable stories. Most commonly among non-Chinese visitors, who came from all over the world, were the stories of childhood memories of visiting Chinatowns, its food (visitors named their favorites) and curios. A few reminisced about their personal experiences with a common scene in the early days: Chinese-Canadian market gardeners who delivered produce to local neighborhoods, and Chinese-Canadian restaurants that continue to dot the landscape in both big cities and small towns in British Columbia. Through this exercise, it emerged Chinatown no longer fitted the previous perception of a secluded community for visitors, but became a place where stories of lived experiences were shared, and where the intercultural lives of Chinese and non-Chinese intertwined.

Unexpectedly, about 5 per cent of visitor feedback did not address the question of the Chinatown experience, but their thoughts enriched our understanding of the diversity of visitors and the educational impact within the transnational context. The comments came in different languages including English, Mandarin, Japanese, Korean, and Arabic. Some comments were quick acknowledgements of being here, but others revealed a potential educational impact: many comments evoked a context which points to the 'final triumphant stage of successive progression' (Macdonald 2003: 2-3) and agreed with the marginalized group's 'worth and contribution,' (quoted in Simpson 1996: 75). 'This is my first time seeing the exhibit of the history of Chinatown. I feel touched. The Chinese in Canada were so great, and had a long history. They are inspiring and respectable.' 'Chinese have made Canada a better place and I am very grateful.' 'Thanks for Canada's multi-cultural society. I enjoy the exhibition!' This strong indication of changed perceptions of a cross-cultural Chinatown history, and positive attitudes toward this educational opportunity, becomes a measurable learning outcome, indicating that TiF succeeded in its educational goal.

Furthermore, within the broader transnational context, the 'hybridities and fluidities' which informed the Chinese-Canadian stories and cultural artifacts connected with visitors of diverse origins through different elements or aspects of museum education. For instance, one comment in Mandarin stated: 'Previously, I didn't care about Chinatown, and thought there were only dirty, messy but good restaurants. To my surprise, they recorded the hard time of the Chinese in early days. I am proud of them and my country!' This sentiment, on one level, illustrates the educational value of these stories to visitors who were unfamiliar with the marginalized history. In addition, this visitor connected with the pioneer spirits of Chinese Canadians, and their strong appreciation for their ancestors, as well as identification with and patriotism for Canada, with spirits that inspired this visitor's patriotism for China. This comment was also indicative of the changing historical context. As opposed to the period when Chinese were excluded in North America without a strong China to support them, today China is one of Canada's largest trading partners, and one of the largest sources of tourists and new immigrants coming to Canada. In both countries, there is an increasing desire for the understanding of the historical connections between them. In China, there has been significant growing academic and public interest in the lives and histories of the overseas Chinese. The contribution and struggles of the previously marginalized Chinese-Canadian communities such as those showcased in TiF can therefore help to promote cross-cultural understanding. 


\section{Museum Education Beyond Exhibition through an ICT Project}

Based on the feedback from visitors, as a curator I wanted to explore the educational opportunities of developing the TiF exhibition research and content to create an information and communications technology (ICT) project that would create a permanent legacy for the exhibit. Coming from academic background, I was shocked to find that although previous multicultural themed exhibitions at the RBCM received positive feedback, other than curatorial and exhibit research files, and at times exhibition catalogues and books, little of the exhibits survived deinstallation. I hoped to repurpose the intricate research and exhibition work of TiF for public education purposes.

The original digital elements from the exhibition, including the lantern itself and its digital animation and the interviews, were only educationally meaningful within the context of the overall exhibition. 'Most digital reproductions only gain depth when they are presented as part of a larger story.... Storytelling creates a sense of space the Web deeply needs' (Müller 2002: 28).

Given this need and desire to reach a broader audience, I consulted with educators and communications and media experts about digitizing the exhibit into a video. Such a project required the co-operation of different departments of the Museum. The Head of Exhibits and I consulted with the Heads of Learning and Digital Preservation, and applied for a grant for this ICT project, which was not built into the exhibit budget. We received the grant in September 2013, commissioned the production team and filmed the physical exhibition before it closed in November 2013.

Specifically in line with the theme and content of this exhibition, this ICT project serves as an experiment for sustaining the momentum of the community synergies, and further engaging new audiences in a form of intercultural museum education. We consulted experienced teachers about how to make this digital video useful for students from kindergarten through to high school. They advised that a 10-to-15-minute video is ideal for use in classroom settings, and a supplementary set of lesson plans and teacher resources would encourage teachers to utilize it. The accompanying educational kit will also allow us to include more of the research information that we were able to include in the exhibit. It will be more than 'a catalog of existing information but will take 'advantage of the fact that contextual information can be available at the same time, and in the same place' (Bandelli 1999: 22). Creating the context and resources in this way also 'move[s] beyond the notion that these are just graphic representations of existing spaces' (Bandelli 1999: 22). The educational kit will also be part of the RBCM's launch of its new learning portal that is designed to make its collection and research available in a format that can be used in schools. In so doing, we hope to address the educational challenge that comes from the relative absence of historical materials on previously marginalized groups and a lack of student interest in the subject of history.

The project is currently (September 2014) in the post-production stage as we prepare to present English, French and Chinese versions in DVD and online video. English and French are the official languages of Canada, and educational materials in both languages are used in school systems; the Chinese version is inherently part of the original exhibition, which we found attracted interests among Chinese visitors. In light of China's increasing interest in overseas Chinese lives and history, this project in museum education aims at broadening intercultural and historical understanding. For instance, Chinese and Chinese-Canadians as terms cannot define the very diverse peoples who can be categorized as such but come from different backgrounds. The topic of this DVD and video explores the real lives and diversities of Chinese-Canadians with family roots connected to China.

Community participation in a local-focus exhibition connected to transnational contexts can bring together and shape imagined communities within transnational and cross-cultural contexts. Museum education in this sense connects to a broader audience than the physical exhibition, and promotes the understanding of the historical and intercultural complexity of this interconnected world. As the exhibition feedback cited in the second section of this essay demonstrates, visitors related and responded to the exhibition from their particular local, national and transnational background.

To inspire interest in our informal education on history and intercultural understanding, the transnational framework of the exhibit therefore could also serve to engage a broader audience 
of the ICT project production, while the digital production required a different story-telling style from physical exhibition to a film. This story-telling transformation, a change of educational format, entailed not direct transfer of data, but a production process that was different from exhibition planning. As the curator of the exhibition I provided the ICT project production team with the exhibition content and additional research and contextual information; they extracted the elements that, from the media perspective, would make an engaging story.

The production process required substantial communication, discussion and negotiation, another form of intercultural and interprofessional communication that has to happen for the goal of intercultural education. The local and transnational context from the original exhibition corresponded with the web context, so that part of the exhibition content was presented clearly from the beginning of the narrative as the framework for the digital production. At the same time, we had to be selective in choosing details from the exhibition. For example, the video production team had space for one segment from each of the five interviews to remake a coherent story. Jon Joe's 10-minute family interview offered many choices. With my academic training and college teaching experience, my instinct was to choose the clip where he spoke about educational segregation, a particularly poignant chapter in provincial history, from his personal experience. For me, that would have served as a great starting point for classroom discussion. The production team, on the other hand, from their communications and media perspectives, chose the clip on his memory of his first encounter with his wife, the development of that life-long relationship, and their common interest in Chinese Opera, on the grounds that that story was more likely to retain viewer interest. I accepted this clip choice but added a critical observation to make historical connections at the end of the segment. When the Head of the Learning Department at RBCM reviewed the draft video, she observed, 'The stories were popular in nature and provide a human element that everyone can connect to, which brings us all together. I call these human touchstones - common to all. ${ }^{15}$ Indeed, this comment resonates with the museum's educational goal of promoting cross-cultural understanding: 'At the same time museums are striving to promote awareness of the value of cultural diversity, they are also 'looking for ways to illustrate, through cultural diversity, our common humanity' (Kreps 2003: 157). With this video as an initial tool to inspire viewer interests, the development of the supplemental educational kit provides the opportunity for in-depth educational impact through engagement with associated historical issues beyond the museum walls.

In this way, the ICT innovations in story-telling created a new narrative in enhancing learning in informal and non-formal museum education to promote intercultural and historical understanding. The ultimate goal of sharing these stories is to engage new audiences, inspire cross-cultural aesthetic sensibilities, explore the connections between the local, national and transnational, and to provide a model of respect and social justice. The heritage project is 'a new mode of cultural production in the present that has recourse to the past' (Kirshenblatt-Gimblett 1998:149). Moreover, web presence can serve as a "catalyst" for starting conversations that we wish to use as the beginning of informal museum education about the works of art' (Bandelli 1999: 22), hopefully for its associated history and culture as well.

Because of its fragility, the Chinese Freemasons Lantern cannot travel, even though there is interest elsewhere in seeing this exhibition. The digital animation film clip of the lantern alone does not convey the historical and cultural significance and connections to lived experiences that the object holds, and therefore the ICT project attempts to provide an accessible narrative, a context to inspire further cross-cultural appreciation for its art, history, and culture. The project goal is to promote a different form of education and discussion through innovative means.

Due to our community engagement and contacts, in the current post-production stage this ICT project has attracted interest from community leaders and overseas institutions to distribute and display the final product. Chinese-Canadian community leaders offered help to distribute the video and associated learning materials to Canadian schools. The memory institutions (museums, libraries and archives) in China are also interested in housing the digital exhibition video for future research. Due to the rising attention on the history of overseas Chinese, a higher education institution coordinator in Canada has also proposed developing a lesson plan in Mandarin for the Mandarin version of the video. At my lecture at Beijing Foreign Studies University on the museum work using TiFas an example, the faculty of Asian-American 
Studies and Chinese-Canadian Studies also expressed strong interest in using this video in their college classrooms. They believed the video, as a seed for educational reflection, would inspire not only school-age children but also their college students to delve deeper into the subject. The community outreach and engagement afforded exciting possibilities that we need to explore in our quest to create new educational synergies among institutions, to engage a broad international audience, to inspire appreciation for the aesthetic achievements of almost a century ago, and to promote intercultural education for justice in an interconnected world.

\section{Conclusion}

Community outreach and engagement and the need for museums to 'assume a leadership role in shaping awareness of and attitudes toward....cultural diversity' (Glaser and Zenetou 1995: 233) informed the Tradition in Felicities exhibition, and remain the keys to the development and distribution of its ICT project and associated educational resources. As museum education scholars attest, 'The next great task for museum educators is to articulate, demonstrate, and document the ways museums change individuals and communities. ${ }^{16}$ With the example of the TiF exhibition, a museum today can indeed engage new audiences and inspire aesthetic sensitivities and historical and cultural appreciation. In addition, museums need to work with regional and global educational and memory institutions to explore new synergies and address new challenges.

This exhibition and essay started with Klaus Müller's question: 'can museums propose or even help shape a different model of a global society than the one being advanced by multinational corporations?' (2003) By measuring the reflections of visitors in regards to their attitudes and values, we begin to get a sense of the success of TiF as an advocate for educating diversity awareness, welcoming non-traditional museum audiences, and applying an audience-centred approach. ${ }^{17}$ Although there was no significant recording-breaking attendance for this exhibit, it did help to build a case for public value. The answer from this case study to Müller's question is therefore yes. Through community outreach and engagement, as well as local, national and transnational collaborations among educational and memory institutions, museums can promote intercultural understanding and social justice.

Received:11 October 2014

Finally Accepted: 6 March 2015

\section{Notes}

1 The term 'felicities' was used to convey the Chinese concept of 节庆, the lively joy from the celebrations of major traditional holidays, especially the Chinese New Year that was the occasion and a main theme of this exhibition.

2 The Chinese Freemason's Lantern is based on the structure of a traditional running (or revolving) horse lantern (走马灯). This kind of lantern uses the air heated by candles or lights to move the horses and other connected parts around a central axis. It has been a popular arts-and-crafts tradition in Chinese culture for centuries, with its earliest record dating back to early Han dynasty (141-202 BC).

3 For this trend, see Müller 2003; for a discussion on the global presence in the local processes of place-making, see Andersson.

4 Kim Gough, personal communication, 15 January 2015.

5 Quoted in Kim Gough, pers.comm, 15 January 2015. See http://www.inspiringlearningforall. gov.uk/toolstemplates/genericlearning/, accessed 15 January 2015.

6 In May 2014, the Legislative Assembly of the Province of British Columbia officially apologized to BC's Chinese Canadian Communities for historical wrongs, which included over 200 discriminatory provincial legislations against ethnic Chinese from 1871 to 1947. 
7 In recent years, $\mathrm{RBCM}$ staff have recognized that its gallery requires renewal partly because it does not recognize the transnational flows that 'generate new hybrid cultures' (Urry 1996: 46) which also inform BC experiences. Before the gallery renewal option becomes possible, we aim to address the diversities and hybridities of the cultures of British Columbia peoples, and their struggles and contribution for intercultural understanding and justice, through temporary exhibitions.

8 Black History Month originated in the U.S. in 1926. The provinces of British Columbia and Ontario were the first to declare February as Black History month in Canada. British Columbia began its celebration in 1993.

9 As a provincial museum, the RBCM receives around a portion of its operating budget from the government and is responsible for fundraising the rest. Within the circumstances, it takes outside support to make exhibition and other project initiatives possible.

10 Victoria Chinese Public School (域多利華僑公立學校), was founded in 1899 and its current building opened in 1909. It is the oldest Chinese school in Canada. Located in Victoria's Chinatown, it now offers after-school and weekend classes on Chinese language and culture.

11 Tina Bebbington, personal communication, 29 April 2013.

12 This school is the oldest Chinese school in Canada that is still operating today. See Amos and Wong, Inside Chinatown.

13 This educational exchange between museum and audience addresses the intersection of the education theories that chart a learner's external and internal constructed knowledge (see Fig. 20.1 in Hein 2006: 346).

14 Bonnie Mar, personal communication, 13 February, 2013.

15 Janet Macdonald, personal communication, 14 February 2014.

16 Munley \& Roberts, 38.

17 Kim Gough, personal communication, 15 January 2015.

\section{Acknowledgements}

I would like to express special thanks to the two editors of this special issue, the two senior reviewers, Dr. Kate Hill, the editorial board of the journal, and Dr. Patricia E. Roy for their constructive feedback and valuable insights; and to Victoria and Vancouver's Chinatown communities and RBCM staff for making the TiF project possible, and the RBCM Learning Team for their collegial and professional assistance.

\section{References}

Amos, R. and Wong, K., (2010), Inside Chinatown: Ancient Culture in a New World, Victoria BC: Touchwood Editions.

Anderson, B., (1983), Imagined Communities: Reflections on the Origin and Spread of Nationalism, London: Verso.

Andersson, M., (2010), 'Provincial Globalization: The Local Struggle of Place-Making', Culture Unbound: Journal of Current Cultural Research, 2, 193-214.

Bandelli, A., (1999), 'Virtual Spaces and Museums', Journal of Museum Education, 24(1\&2) $20-2$. 
Clouse, A., (2008), 'Narratives of Value and the "Antiques Roadshow": A Game of Recognitions,' Journal of Popular Culture 41(1) 3-20.

Daugbjerg, M. \& Fibiger, T., (2011), 'Introduction: Heritage Gone Global, Investigating the Production and Problematics of Globalized Pasts,' History and Anthropology, 22(2) 135-47.

Fishkin, S. F., (2005), 'Crossroads of Cultures: The Transnational Turn in American Studies-Presidential Address to the American Studies Association, November 12, 2004', American Quarterly, 57(1) 17-57.

Fishkin, S. F., (2006), 'Asian Crossroads/Transnational American Studies', The Japanese Journal of American Studies, 17, 5-52.

Hein, G. E., (2006), 'Museum Education', in Sharon Macdonald (ed) A Companion to Museum Studies, 340-52, Oxford: Blackwell.

Karp, I. and Lavine, S., (eds), (1991), Exhibiting Cultures: The Poetics and Politics of Museum Display, Washington, DC: Smithsonian Institution Press.

Kirshenblatt-Gimblett, B., (ed), (1998), Destination culture: Tourism, museums, and heritage, Berkeley: University of California Press.

Kreps, C. F., (2003), Liberating Culture: Cross-cultural Perspectives on Museums, Curation and Heritage Preservation, London: Routledge.

Lai, D. C., (1994a), 'The Chinatown Exhibit of the Royal British Columbia Museum,' Journal of the B.C. Historical Federation, 27(2) 32-3.

Lai, D. C., (1994b), 'Curatorial Statement of Royal British Columbia Museum, Victoria: Chinatown', Material History Review 40, 77-8.

Macdonald, S. J., (1996), 'Theorizing Museums: An Introduction' in S. Macdonald and G. Fyfe (eds), Theorizing Museums: Representing Identity and Diversity in a Changing World, 1-18, Cambridge, MA: Blackwell.

(2003), 'Museums, National, Postnational, and Transcultural Identities,' Museum and Society, 1(1) 1-16.

Munley, M. \& Roberts, R., 'Are Museum Educators still Necessary?', Journal of Museum Education, 31 (1) 29-40.

Müller, K., (2002), 'Museums and Virtuality', Curator, 45(1) 21-35.

(2003), 'The Culture of Globalization', American Association of Museums Museum News, 82 (3), 34-9, http://kmlink.home.xs4all.nl/09newarticles/13globalization.htm, accessed 25 February 2014.

Nederveen Pieterse, J., (1997), 'Multiculturalism and Museums: Discourse about Others in the Age of Globalization', Theory, Culture \& Society, 14, 123-46.

Roy P., (1989), A White Man's Province: British Columbia Politicians and Chinese and Japanese Immigrants 1858-1914, Vancouver: UBC Press.

(2003) The Oriental Question: Consolidating a White Man's Province 1914-41, Vancouver: UBC Press.

Simpson, M., (1996), Making Representations: Museum in the Post-Colonial Era, London: Routledge. 
Urry, J., (1996), 'How Societies Remember the Past' in Sharon Macdonald and Gordon Fyfe (eds) Theorizing Museums: Representing Identity and Diversity in a Changing World, 45-65, Cambridge, MA: Blackwell.

Weil, S. E., (1999), 'From Being about Something to Being for Somebody: The Ongoing Transformation of the American Museum', Dædalus: Journal of the American Academy of Arts and Sciences, 128 (3) 229-58.

*Tzu-I Chung is Curator of History at the Royal British Columbia Museum (RBCM) in Victoria, BC, Canada. She received her Ph.D. from the University of Arizona, and has taught history, media studies and cultural studies classes in American universities. Her museum project, the Centre of Arrivals, is part of the RBCM's long-term commitment toward exploring and representing the stories of diverse immigrants in British Columbia through research, collection and exhibits. Her current research focuses on the intercultural food history of British Columbia within the context of historical, cultural, and economic exchange between North America and Asia, and on transnational migration theories.

Dr Tzu-l Chung

675 Belleville Street,

Victoria, BC

Canada V8W 9W2

T $250880-1760$

F $250387-0533$

TChung@royalbcmuseum.bc.ca 